\section{NESTOR \\ A Mediterranean \\ Neutrino Telescope}

Proponents of a neutrino telescope for the Mediterranean argue that the convergence of particle physics and astrophysics calls for an European underwater observatory to complement two major high-energy particle physics laboratories (CERN and DESY), and the Gran Sasso underground laboratory in Italy. NESTOR, in stretching the name of the wise king of Pylos who counselled the Greeks during the Trojan war, to stand for "NEutrinos from Supernova and $\mathrm{TeV}$ sources, Ocean Range", has like DUMAND, the goal of building a high-energy neutrino telescope for muon detection, only significantly larger for greater sensitivity (covering $10^{5} \mathrm{~m}^{2}$ versus $2 \times 10^{4} \mathrm{~m}^{2}$ ) but retaining a resolution of $1^{0}$. A $3800 \mathrm{~m}$ deep plateau with comparable oceanographic characteristics to the DUMAND site was fortuitously found remarkably close to the Greek mainland some $11 \mathrm{~km}$ from Pylos. There is room to extend the proposed array across the triangular plateau which has sides at least $6 \mathrm{~km}$ long. Attenuation is $35 \pm$ $10 \mathrm{~m}$ at $4500 \AA$ down to $4200 \mathrm{~m}$ a few $\mathrm{km}$ further out to sea and the mean current is $<50$ $\mathrm{mm} / \mathrm{s}$ (although long-term measurements are required).

A Russian-built, $14 \mathrm{~m}$ in diameter, hexagonal structure supporting 10 scaled-down versions of a final phototube design was deployed in July 1991 to $4100 \mathrm{~m}$. It gave vertical muon intensities and an angular distribution of down-coming muons in agreement with DUMAND I results (see page 167). Tests starting last month used tubes facing downwards to refine the detector design for upcoming muons. Geometry is not yet optimised for the full $10^{5} \mathrm{~m}^{2}$, but preliminary calculations call for a hexagonal $100 \mathrm{~m}$ array of seven towers comprising a sacked arrangement of the basic hexagonal element, with its unique folding arms which are kept extended underwater by the buoyancy of the attached detector modules. The mechanically and electrically independent towers with a sensitive reach of at least $30 \mathrm{~m}$ would each comprise 12 elements spaced $40 \mathrm{~m}$ apart. The design of the detector modules with a $4 \pi$ response is proven, having profited from close collaboration with the DUMAND team. Professor Leo Rasvanis of the Physics Lab., University of Athens [tel.: +30 (1) 36334 14],

Professor Leo Rasvanis, who heads the NESTOR Colllaboration.

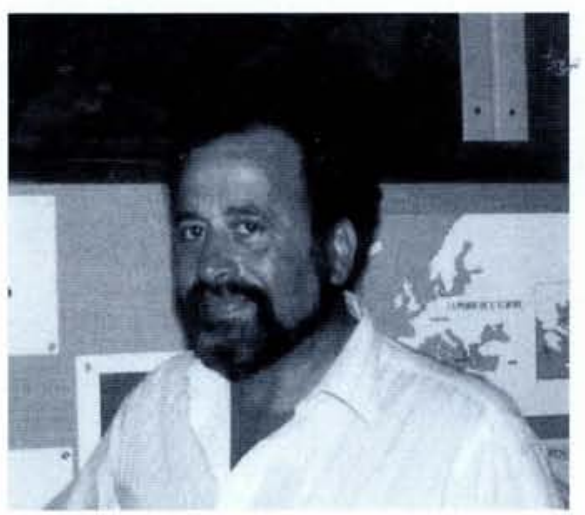

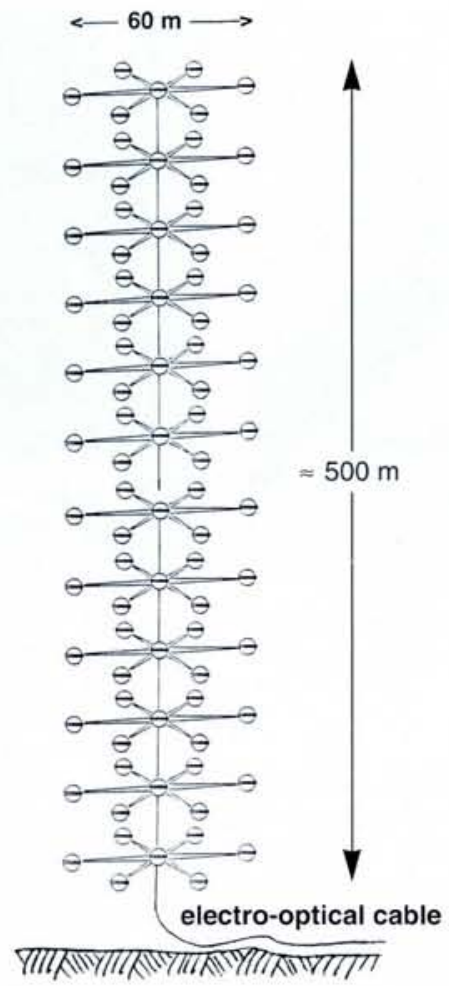

A schematic illustration of a NESTOR tower: the spherical detector modules are supported at the ends of hexagonally arranged arms that make up the basic element. The $500 \mathrm{~mm}$ high tower would be suspended at depth of $3800 \mathrm{~m}$.

heads the NESTOR Collaboration. He believes the final array could be built for $14 \mathrm{M}$ SUS. But this depends greatly on the price of the intelligent phototubes in the detectors. Suppliers are limited to two western companies and a Russian agency.

The collaboration has $2.5 \mathrm{M}$ SUS for three years from $\mathrm{EC}$ regional development funds to be spent by 1994, and matching resources

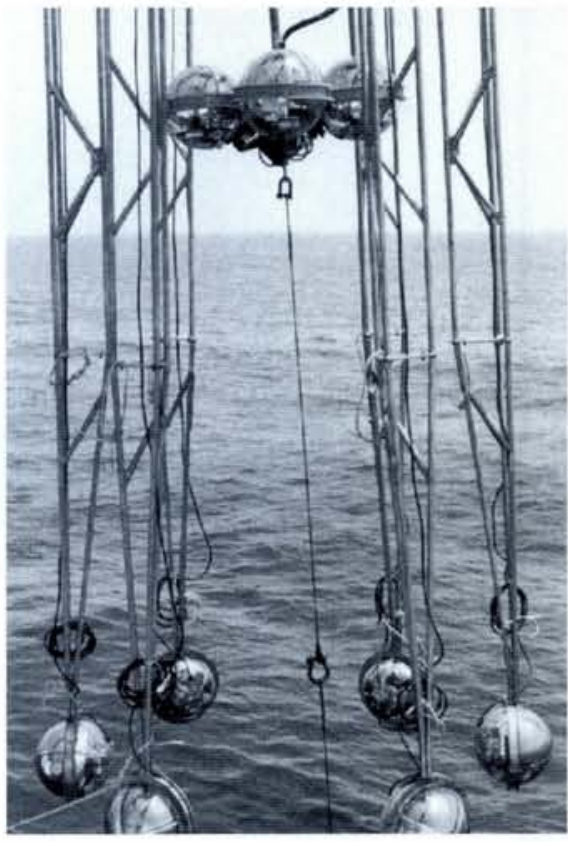

The $14 \mathrm{~m}$ diameter prototype of the basic NESTOR detector element in the collapsed state just before deployment and extension of the arms underwater for data taking in July 1991.

from the Greek government, for a single tower, first-step array of $3 \times 10^{4} \mathrm{~m}^{2}$ and for setting up the shore station in a former school. The Institute of Nuclear Research, Moscow, and the Institute of Oceanology, Moscow, are supplying phototubes and the oceanographic vessel for deploying the tower. One tower is insufficient for obtaining an astrophysically relevant signal from point sources so the hope is to build an intermediate array by 1994 and the final array by 1997. Apart from the on-going trials, the NESTOR collaboration is seeking further support via regional aid programmes that would underwrite the local manufacture of key components.

\title{
Consolidating Efforts
}

The East-West Coordination Committee (EWCC) of EPS met with the American Physical Society's (APS) Committee on International Scientific Affairs (CISA) in Amsterdam on 3 October for the first time. The aim was to review the outcome of the EPS-APS workshop held in Budapest in May where a joint action plan had been decided [EN 23 (1992) 135] on ways to alleviate the crisis in basic science in east and central Europe (E\&CE) and the republics of the former Soviet Union (FSU).

Concerning journals: the APS has shipped 20 sets of recent back-issues of APS journals to institutes in the FSU and another 8 full sets have been sent to the EPS Secretariat in Budapest for transfer to appropriate sites in E\&CE nominated by national representatives on EWCC. The sets amount to about 200 journal subscriptions: APS plans to continue support at a similar level by providing current journals through a long-standing matching member scheme so that subscriptions can be tailored to institute requirements. Some 200 colleagues from the FSU have been nomi- nated and EWCC is to make an E\&CE list. A selection will be enrolled as APS members and allocated journal subscriptions for one year. The programme, funded by the US National Science Foundation, APS, and the Sloan Foundation, will be reviewed annually and phased down as institutional subscriptions are recovered.

The APS is participating in a grant application geared at recovering roughly one-half of the institutional library subscriptions lost over the last two years. Meanwhile, Maurice Jacob, the President of EPS, presented a proposal to the Commission of the European Communities on 25 September for funds to provide library subscriptions to the FSU. The outcome depends on the final arrangements agreed to by the EC Ministers for handling FSU support in basic science following the Mitterand-Rubbia initiative [EN 23 (1992) 70]. At least three alternatives may be considered, the most promising being the creation of a special foundation or "association". EWCC presented at the the same time a proposal for funding journal subscriptions in 


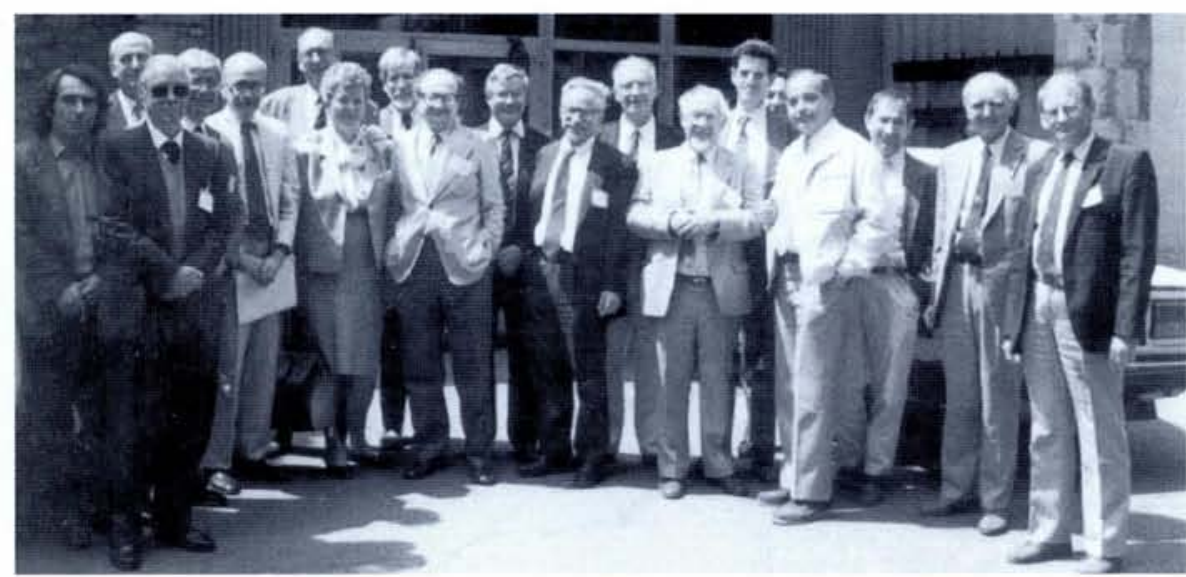

Participants at the meeting of the European (EPS) and American (APS) Physical Soceties, Budapest, 25-27 May 1992. From the left: A. Minxhozi (Tirana); D.N. Langenberg (Adelphi); W.O. Lock (Geneva); M.D. Mateev (Sofia); W.A. Blanpied (Washington D.C.); E.W.A. Lingeman (Amsterdam); E. Thomas (EPS); I.A. Lerch (APS); P. Hohenberg (Murray Hill); M. Jacob (Geneva); E.M. Henley (Seattle); I. Slaus (Zagreb); J. Ziman (Aylesbury); A. Landsman (Paris); N.R. Werthamer (APS); A. Calboreanu (Bucharest); J. Spalek (Warsaw); N. Kroo (Budapest); J. Nadrchal (Prague). Not shown: I. Abonyi (Budapest); L. Baksay (Tuscaloosa); G. Ripka (Saclay. APS participants in italics.

E\&CE under the EC's Cooperation in Science and Technology with E\&CE (COST) programme. The proposal is based on the EPS library survey which remains the most complete catalogue of needs. COST's budget of about $50 \mathrm{MECU}$ is oversubscribed by a massive $3000 \%$ so the EWCC must await a decision on the 1993 EC budget, and a possible allocation to COST next spring.

A large part of the discussions were centered around telecommunications. Institutes in Poland, Czechoslovakia and Hungary can

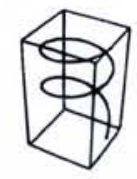

\section{Mathematica}

TM

A system for Doing Mathematics by Computer

A Wolfram Research Inc. product

Numerics - Works with numbers of arbitrary magnitude and precision.

Symbolics - Encyclopaedia of mathematical functions and operations used in arithmetic, algebra and analys. Procedural, functional and mathematical programming.

Graphics - 2D, 3D and animated PostScript graphics

Text processing - Fully interactive reports and textbooks.

Runs on - MS-DOS based computers; Macintosh, Apollo, Hewlett Packard, IBM AIX/RT, MIPS, Silicon graphics, Sony, Sun, VAX

Now available in Europe from:

MathSoft Overseas, Inc.

POB 641, 1211 Geneva 3, Switzerland Tel. +41 (22) 3465260

Fax +41 (22) 3465939 now be reached by electronic mail and there are efforts to connect Bulgaria and Romania to academic networks. Owing to old-fashioned telecommunication networks, fast data transport is still impossible and servers in the west cannot be easily accessed. It was decided to set up a task force to identify bottlenecks and to see how to improve things.

It is extremely important to know how much physics is actually done in E\&CE and the FSU. The first step has been to make an inventory of all physics (research) institutes
Published by the in E\&CE and a 250-page directory called Physics Institutes in Central Europe is about to be printed; it can be ordered in advance from the EPS Secretariat, Geneva (price: SFR 120.-). The printing of directories covering the Baltic states and the FSU based on data collected in collaboration with CISA is foreseen for spring 1993. It is hoped to have all three databases electronically accessible at some stage, possible in conjunction with EPS databases comprising, e.g., information for operating the student mobility scheme.

The issue of centres of excellence is an important though sensitive item. A good deal of nervousness was evident about the implication that EPS/APS should certify institutions that aspire to be "centres of excellence", the suggestion being to develop certification criteria. The general opinion was to encourage colleagues to think in terms of "centers without walls", i.e., to develop working relations, including some division of labour, among good but sub-optimal groups in different countries that might collectively attract western scholars and students. The two societies could publicise such arrangements and assist them to obtain funds to bring in scholars and students for substantial periods of time. All agreed that the words "centre of excellence" should not be used to denote a good physics centre. On the other hand, when a physical society wants to invite an external panel to evaluate a centre, APS and EPS should provide appropriate candidates based on a list of peer reviewers. A working group will be appointed to prepare a background paper.

E.W.A. Lingeman Secretary, EWCC

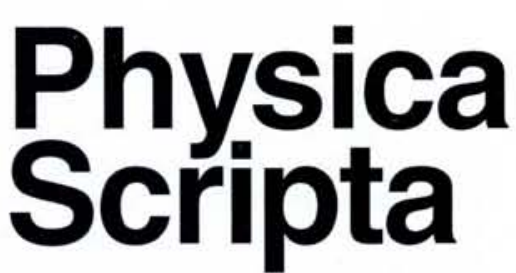

An international journal for experimental and theoretical physics

Vol. T43 1992

\section{Extragalactic Astronomy including Observational Cosmology \\ Proceedings of the 1991 Crafoord Symposium}

Stockholm, Sweden, 25-26 September 1991 Editor: A. Elvius

The 1991 Crafoord Symposium honoured Dr. Allan R. Sandage of The Observatories of the Carnegie Institution, Pasadena, CA, USA, winner of the 1991 Crafoord Prize of the Royal Swedish Academy of Sciences. The Proceedings comprise contributions by: A.R. Sandage on the curvature of space and cosmic expansion; G.A. Tammann on deviations from cosmic expansion; J. Silk on the cosmic microwave background and large-scale structure; A. Shaver on radio galaxies and quasars; L.B. Bảảth on active galactic nuclei; and N. Bergvall on young galaxies.

70 pages in all

Orders to Physica Scripta at the address shown below; Price: SEK 105.-

ROYAL SWEDISH ACADEMY OF SCIENCES

Box 50005

S - 10405 Stockholm / Sweden

ISSN 0281-1847

ISBN 91-87308-94-0 